\title{
In the Belly of the Beast: A Case Study of Social Work in a Managed Care Organization
}

\author{
Lisa S. Patchner
}

\begin{abstract}
The employment of social workers within managed care organizations is a new phenomenon. As such, this case study utilized an exploratory-descriptive design that assessed social workers as case managers within a Medicaid HMO. The semi-structured interviews, focus groups, and participant observation suggested that the use of casemanagement services, delivered primarily by social workers, was effective in addressing the bio-psychosocial needs of Medicaid consumers within a provider-driven HMO. Study findings recommend specificknowledgeand skillsthat social workers need in order to prepare for practice within managed care environments.
\end{abstract}

Keywords: Managed care; Medicaid; case management; HMO, health care policy

A s managed care more completely penetrates the health care and public service delivery markets, the industry can expect to enroll increased numbers of high-risk populations. With advances in medicine, coupled with the aging of the population, there are increased numbers of individuals with chronic illnesses and complex psychosocial concerns that require long-term health and community-based services(U.S. General Accounting Office, 1996). Themanaged care industry, familiar with the provision of a lower-cost alternative to traditional indemnity insurance for healthy populations, has limited experience serving high-risk populations (Kaiser Commission, 1995). As Kelly (1997) reported, most managed care companies are inexperienced in the supply of community support services (i.e, psychosocial services, outreach, case management, and transportation) needed to manage health care and promote wellness among high-risk populations. With the increased privatization of Medicaid, leading to managed care arrangements, the industry has had to hasten delivery systems to meet the health and social service needs of a growing, heterogeneous population.

Even though managed care continues to grow at a rapid pace, there have been no empirical studies of social workers' involvement in private managed care organizations. This study represents a beginning attempt at understanding professional social work involvement in the evolving managed health care delivery system by examining social workers employed in a Medicaid managed care organization. Specifically, this case study investigated the role and functions of social workers in a

Lisa S. Patchner, DrPH., LSW., ACSW is Associate Professor, Social Work Department, Ball State University, Muncie, Indiana 47306-0525.

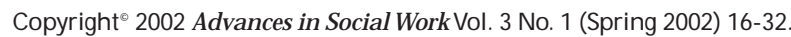

Indiana University School of Social Work. 
Medicaid managed care organization, and determined the structure and function of case management services offered by thesesocial workers. Implications are drawn for social work's involvement in managed care organizations and for the education of future professional social workers for case management positions within managed health care organizations.

\section{BACKGROUND}

Managed care will increase its penetration into the continuum of care in order to demonstrate efficient and cost-effective health improvement for large, chronically ill populations (Goldsmith, Goran \& Nackel, 1995). Expansion into the provision of community services alters the treatment focus from acute care to chronic care, and highlights the need for cost-effective, long-term care management of the chronically ill and other high-risk consumers (Moore-Greene, 2000).

Social work case management models have traditionally been applied in the coordination and linkage of service components within the service delivery continuum. In providing case management services, social workers transition highrisk clients with chronic illnesses to appropriate levels of care in order to increase desired health outcomes and decrease inappropriate utilization of services. Traditionally found within community service settings, case management services have begun to emerge as an important component of insurance utilization management. Managed care systems have begun to integrate case management strategies into their organizational processes in order to coordinate acute and chronic care services for increased Medicaid enrollments (Kaiser Commission, 1995). As Medicaid managed care systems provide the consumer with a primary care provider and facilitate the coordination of integrated services through case management services, better population health outcomes should emerge.

According to a recent Health Care Financing Administration (HCFA) Press Office Fact Sheet on Managed Care in Medicare and Medicaid (U.S. Dept. of Health and Human Services, 1997), enrollment in managed care plans has experienced unprecedented growth. In 1999, more than half (55.59\%) of the national Medicaid population was enrolled in a managed health care plan (U.S. Dept. of Health and Human Services, 2000). The accelerated growth of Medicaid managed care systems, which serves the most vulnerable populations, is the result of a failure to agree upon a national health policy, increased fiscal deficits, and inequalities of access to primary medical care.

Most states have focused their managed care enrollments on low-incomefamilies, which constituted approximately 73\% of the Medicaid population in 1994 (U.S. General Accounting Office, 1996). Asstates initiate mandated managed care for their entire Medicaid populations, individuals with disabilities, who represented approximately $15 \%$ of the 1994 Medicaid population and account for more than one-third of Medicaid expenditures, will also challenge states to provide quality health care to a diverse population. Additionally, the prevalence of chronic illnesses and disabilities among children enrolled in the former AFDC and current TANF programs is approximately twicethat of children from the general population (Meyers, Lukemeyer \& Smeeding, 1998). According to a recent study (Shatin, Levin, I reys \& Haller, 1998), children with selected chronic health conditions are enrolled at a higher 
ratein Medicaid managed care plans than in private managed care plans, and those enrolled in Medicaid managed care plans require moreservices than children with similar conditions who are enrolled in private managed care plans. Due to the heterogeneity of chronic disabling conditions and demographic trends, individuals with chronic illnesses and disabilities will need a well-designed service delivery continuum (The Institute for the Future, 2000). Somers and Martin (1997) state:

Health plans entering the Medicaid marketplace must adapt their health care delivery systems to serve the disabled and aged populations. Purely medical-model health care delivery systems must become social-model organizations able to coordinate both medical care and social services. (p. 2)

A series of recommendations is beginning to emerge from advocacy, research, government, and industry experts indicating that a refined and informed approach to meeting the unique health care needs of high-risk populations, including those with chronic health care needs, is urgently needed. The Kaiser Commission (1995) asserts that the special needs, ethnic characteristics, and other unique features of the Medicaid population must be addressed when designing effective managed care systems for low-income consumers. Their report further indicates that such services as case management and care coordination have the potential to improve health delivery by modifying managed care services to address unique health concerns.

ThePew Commission (1995) predicts that the future American health caresystem will be more concerned with disease prevention, health promotion, and care management, and less focused on specific medical treatments. The Commission recommends that health professionals broaden their understanding of the psychosocial-behavioral sciences, population health promotion strategies, and health management sciences in order to better meet national health needs. The Pew Commission also asserts that the newly emerging demand-driven health care system warrants consumer-focused and culturally-sensitive health care delivery.

Preister (1996) recommends a new model of consumer-focused delivery that incorporates four characteristics: community-based human services; flexible and holistic services; family-centered services; and professional services that reflect accountability. Additionally, Preister (1996) stresses that families need to partner with case managers to design consumer-focused interventions.

McManus, Fox, and Newacheck (1996) acknowledge the important contributions of case management services to families of children with special health needs. According to Nicolaysen (1996), the need for case management within managed care will continue to grow as wellness among high-risk populations is promoted, thus indirectly reducing costs and contributing to cost containment. Harris (1992) anticipates that in addition to educating consumers about health prevention, there will be more emphasis on improved health outcomes by better management of clinical interventions. Others predict that managed care will focus more upon managing health outcomes of high-risk populations (Goldsmith, et al., 1995; U.S. GAO, 1996).

As managed care better adapts its service delivery systems to address the needs of high-risk populations, increased opportunities for professional case managers 
will emerge. Although various professions have provided case management services, social workers continue to be most commonly associated with case management, especially at the community level. The National Association of Social Workers (1992) defines social work case management as:

A method of providing services whereby a professional social worker assesses the needs of the client and the client's family, when appropriate, and arranges, coordinates, monitors, evaluates, and advocates for a package of multiple services to meet the specific client's complex needs. (p.5)

Long familiar to social workers, case management has grown in importance in health care due to the changing health needs of the population and the resulting changes in health delivery systems. Landgarten (1988) argues that the growth of case management services reveals the fragmentation and inefficiencies throughout the health care delivery system. He asserts that case management attempts to reintegratethe fragmented health delivery system to meet the convergent needs of the consumer, payers, and providers.

As the U.S. population is increasingly covered under managed health and welfare services, the expertise of social work case managers in serving high-risk populations will be sought out by the private managed care sector. Social workers are specifically trained to utilize tested interventions from community-based programming and adapt these to managed care settings in order to deal with problems of access to services, continuity of care, and chronic care management (Hughes, 1999). Despite these opportunities, social workers have generally avoided working for managed care organizations even though their knowledge, skills, and values could greatly benefit persons served by these plans. Reluctance on the part of professional social workers to seek employment in managed care systems is due, in part, to an historical aversion to participate in the for-profit sector of the economy. In addition, the ethical issues surrounding cost-containment measures implemented by these systems have made them suspect to the profession. However, due to their specific skills and training, social workers can make significant contributions to the availability, accessibility, and quality of services provided through managed care arrangements.

\section{METHODOLOGY}

This case study examined social workers in a Medicaid managed care system and described the unique applications of social work case management services in this environment. Specifically, the study had two major foci. The first was to analyze the role and functions of social workers in a Medicaid managed care organization serving the western region of a Middle Atlantic state. The second was to describe the structureand function of case management within a Medicaid managed care system.

\section{Setting}

A for-profit, managed care organization that delivers an HMO product specifically designed for the Medicaid population served as the setting for the study. The health plan began in November 1992, when an Agreement and Plan of Limited Partnership was signed by three major health care organizations. Two of the three partners are not-for-profit organizations and thethird is for-profit. The health plan 
began enrolling Medicaid recipients in July 1993 with a start-up population of 111 , and at the time of this study, covered more than 102,000 beneficiaries. The health plan began serving one county and expanded to a 16-county area. As a network model $\mathrm{HMO}$, the health plan concentrated on developing a quality provider network with a strong internal utilization management structure during its early development. As membership increased, attention to both the external and internal delivery process led to further refinement of health services, specialized case management, quality improvement techniques, and utilization management. Incrementally, health improvement strategies utilizing disease prevention programs (i.e., asthma program, maternal health program), member education, and targeted case management were implemented. This particular Medicaid managed care organization was selected for study because they had a unique Case Management Unit where social workers played an integral part in the delivery of case management services to a high-risk Medicaid population.

\section{Design}

Given the complexity of case management, several data collection methods were employed. These included interviews with case managers and the MSW Manager of the Unit, focus groups with consumers, and participant observation.

Face-to-face interviews were held with eight case managers. Five were MSWlevel social workers, two were BSN-level nurses, and one was a MS-level Rehabilitation Counselor. The interviews focused on assessing their specific roles and functions and ascertaining the model of intervention that they employed. Semi-structured interviews allowed for in-depth questioning about the case managers' specific roles and functions, and their use of case management interventions. Each interview occurred at the case manager's workstation and took approximately 45 minutes to complete.

In addition, this investigator engaged in participant observations of the operations of the Case Management Unit. These day-long observations occurred oneto-two days a week for a 15-month period. The purpose of these observations was to gain a comprehensive understanding of the structure, function, and practices of the Case Management Unit at the health plan. This research was authorized by the Managed Care Organization for the purpose of sharing information regarding their Social Case Management Model with other stakeholders. The researcher was not monetarily subsidized by the Managed Care Organization for this research.

During the 15-month period, the investigator interacted with a variety of staff within the Medicaid health plan and attended departmental staff and other corporate meetings that addressed case-management related activities. The researcher was given a cubicle, limited access to the management information system, and a telephone within the Case Management Unit to better assess the operations and processes of the department and to participate more fully with thestaff. The researcher signed a confidentiality statement pledging not to disclose identifying information about any of the cases. Staff routinely shared case situations with the researcher. Observations were noted either in writing through daily field notes or mentally. Daily field notes included the activities of the investigator and impressions of the observations being made, such as how case management was conceptualized and carried out. 
Two focus groups were held with consumers who had recently received case management services to evaluate their satisfaction with those services and their perceptions of their health status. The focus groups were designed in such a manner that those individuals who directly interfaced with a case manager (i.e., they had telephone or face-to-face contact with a case manager) were invited to one group (Focus Group A) and those who did not interface with a case manager (i.e., case management services were provided, but the individual had no direct contact with the case manager) were invited to the other (Focus Group B). All focus group members were chosen from a systematic random sample of recently closed case management cases. Two other selection criteria for participation in the focus groups were residency in the primary county served by the health plan and current membership in the health plan. Application of these criteria resulted in a pool of 36 potential participants for Focus Group A and a pool of 26 for Focus Group B. Attempts were made to phone all of the eligible members to invite them to participate in the focus groups. Those contacted were assured that their participation was voluntary and that their anonymity was guaranteed. Those who were unable to participate indicated a variety of reasons including: work schedules, child care issues and not wanting to participate. Approximately one-third of the eligible focus group members were unable to be reached by phone. Letters inviting participation in the focus groups were sent to all eligible focus group members, except those who declined to participate. Seventeen people accepted the written invitations and participated in the process: 12 participated in Focus Group A and five in Focus Group B.

Free transportation to and from the focus group meetings was provided to any participant who needed it, and each participant was given $\$ 20.00$ for participating in the focus group. Focus groups were held at the corporate office of the health plan and lasted for two hours each. The following areas of inquiry were addressed: the consumers' views of the health plan, case management services, case managers, medical services provided, and past and present health status.

\section{FINDINGS}

\section{Case Management Process}

By its very function of providing and coordinating services to consumers, social work case management within health care delivery uses a client-driven approach to meet consumer health needs. Case management services at this health plan accomplished this by focusing their interventions on client-centered needs by coordinating services, communicating health concerns, educating consumers about health promotion, advocating for necessary services, assessing health needs, and informing consumers about care options.

The traditional case management model that uses a client-driven approach is in sharp contrast to the provider-driven approach which has increased in recent decades due to accountability and profitability factors. At this health plan, a very structured, client-driven approach was in operation within the Case Management Unit, where individual consumer health care needs were the primary focus of the case manager's intervention. 
To bridge the client-driven and provider-driven approaches to case management services, the Case Management Unit adapted a practice model developed by the Case Management Society of America (CMSA) (Smith, 1995). This model places the case manager as the central figure who addresses the various concerns and desires of client, provider, and payer in order to develop effective services. The CMSA model directed case management practice, interventions, and services to meet consumer needs within the managed care health delivery environment, where mediation between the payer, provider, and client occurs. Advocacy, assessment, collaboration, communication, coordination, empowerment, evaluation, facilitation, planning, and problem solving are utilized by the case manager to broker resources for the member of the health plan.

Case management services focused on intervening with complex, catastrophic cases that benefited from increased coordination of medical and communitybased services. Using a bio-psychosocial assessment to determine medically necessary care, case managers assisted the members in accessing health and social services through advocacy, coordination, monitoring, counseling, and education functions. The case management process consisted of referrals, screening, assessment, intervention, and quality monitoring (see Figure 1: Case Management Decision-Making Process).

High-risk cases were routed by utilization nurses, customer services, marketing, providers, members directly, and community-based services to the Case Management Unit. The referral process was accomplished through the management information system, which allowed internal routing of cases on-line rather than on paper. Cases with specific psychosocial and medical indicators were automatically referred to the Case Management Unit for assessment and, if necessary, intervention.

When personnel within the health plan, community providers, or the health plan members themselves identified a psychosocial need, cases were routed to the Case Management Unit for intervention. Certain illnesses or conditions, such as mental illness or substance abuse, automatically triggered a referral. When a referral was made to the Case Management Unit, the member was assigned to a specific case manager who provided the necessary intervention. The case managers were assigned to specific cases where their expertise in behavioral health, highrisk pregnancy, geriatrics, rehabilitation, developmental disabilities, cancer, or HIV/AIDS was needed.

Once a referral was received, a screening was performed to assess health plan eligibility, case management criteria eligibility, and member's willingness to participate with case management. An assignment of the member, based on diagnosis and caseload, was made to a specific case manager. The BSW Intake Coordinator, in consultation with the Manager of the Case Management Unit, made these assignments. Next, the case manager completed a bio-psychosocial assessment. The assessment was done in narrative format on-line. The case manager then assigned a level of case intensity-general, moderate, or complex. These case intensity levels depended upon the amount of time and effort that the case manager would be involved with the case. A plan of care was then developed in conjunction with the health plan member, the family, and/ or the provider. 
Figure 1: Case Management Decision-Making Process

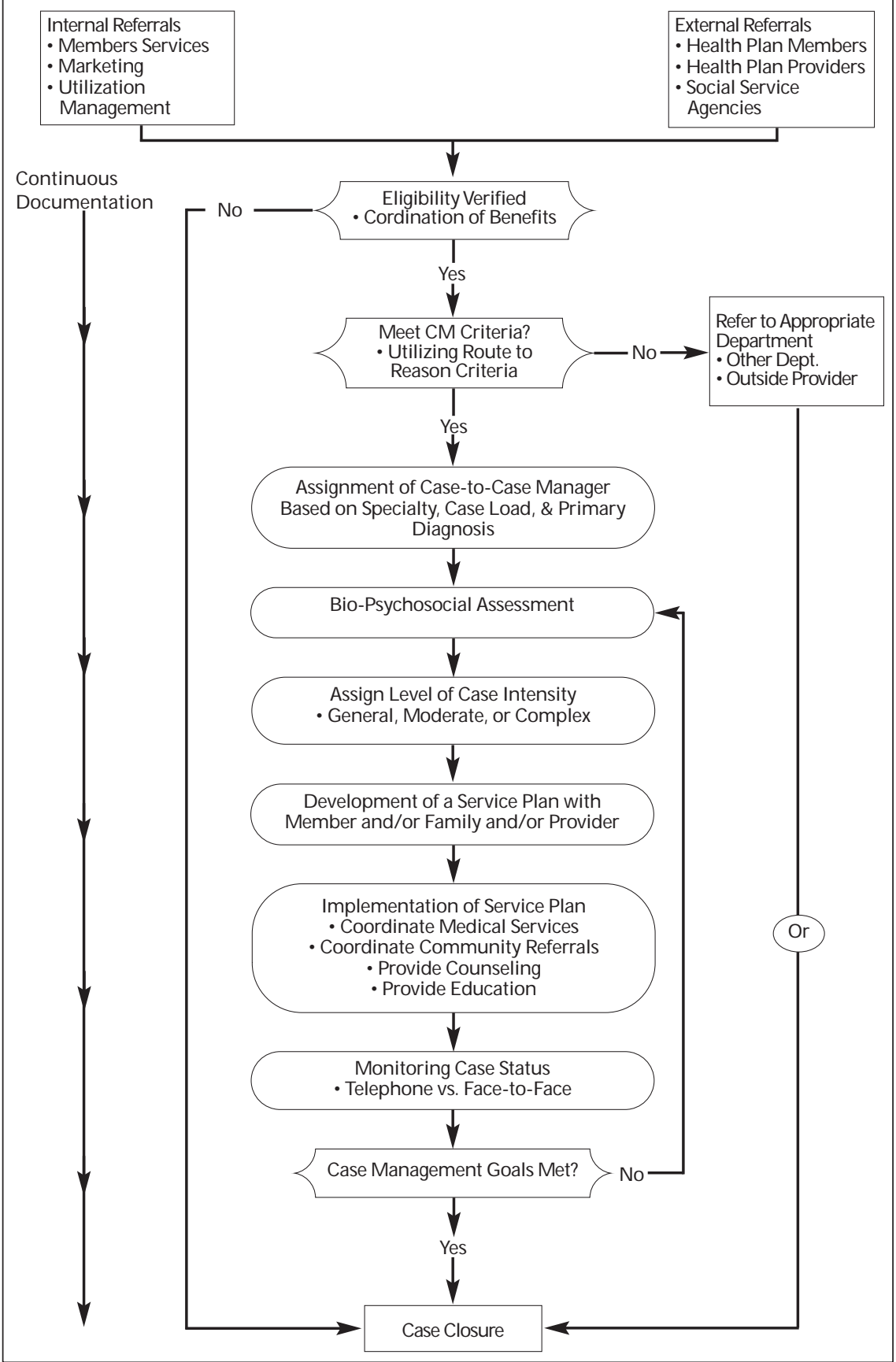


The case manager coordinated the implementation of the interventions specified in the plan of care. This required a variety of contacts with medical and community services and the member and the family. Throughout this process, the case manager strived for the self-determination of the member through education and counseling of the member regarding service alternatives. On-going monitoring of cases to determine whether treatment goals had been met was an integral component when implementing interventions.

Regardless of the professional orientation of the case manager, services were initiated when there was an onset of chronic or catastrophic illness or injury that required coordination of multiple medical and psychosocial needs. It was essential that the case manager focus on an individual treatment plan that was costeffective, satisfying to the consumer, and guided by professional standards. Complex medical referrals of consumers were routed into the Case Management Unit for individualized attention and action by a case manager who addressed the multiple psychosocial needs that impeded medical treatment. Due to the complexity of health care delivery, case management services had grown into a powerful tool for managing the health needs of high-risk populations that exhibited multiple bio-psychosocial needs.

Quality monitoring was a continuous process where case reviews on intensive cases were presented within the department or discussed with the manager of the Case Management Unit. Case management activity was monitored weekly through the management information system documentation to determine the case manager's workload and efficiency in processing the cases. Monitoring of phone calls for quality assurance purposes and adherence to corporate standards were available to managerial staff. An audit, conducted quarterly, was designed by case management staff to assess the quality of the case manager's interventions and documentation through peer and supervisory review.

\section{Consumers Served by Case Management}

At the time of this study, the health plan served more than 102,000 individuals within a 16-county network. Since the inception of case management MIS data collection capability, the Case Management Unit received 16,713 referrals, which included 3,502 separate individuals. These individuals accounted for $3.5 \%$ of the membership in the health plan. Of those served by the Case Management Unit, $70.2 \%$ were female and $29.8 \%$ were male. Their ages ranged from newborn through 95 years of age, with a median age of 25.6 years and a mean age of 28.9 years. For their primary care physicians, $42.6 \%$ of the members who utilized case management services chose family practice physicians, $40.4 \%$ chose internal medicine physicians, and $17.0 \%$ chose pediatricians. These health plan members, all of whom were Medicaid recipients, fell into 45 Medical Assistance categories. These include 33.2\% AFDC_Cash Medicaid, 20.1\% SSI —Disabled, 8.1\% Disabled Elderly, 7.0\% General Assistance or Chronically Needy, 6.9\% AFDC-Medicaid No Grant, 1.4\% SSI-Aged, $16.3 \%$ Not Classified, and $7.0 \%$ that were dispersed among the remaining categories.

Of the 16,713 referrals, $69.9 \%$ came from the health plan Utilization Management Unit, $11.4 \%$ from the Behavioral Health Unit, 4.0\% from community agencies, $3.7 \%$ from the health plan maternity program, and $2.5 \%$ from a self- 
referral or a referral of a family member. The remaining $8.5 \%$ came from social workers in hospitals, rehabilitation units, nursing homes, and home health agencies, OB Clinics, Primary Care Physicians, member services within the health plan, and several other sources.

Each time a member was routed for services, the member's diagnosis was recorded for each specific episode of care. A member's diagnosis could vary each time the Case Management Unit was involved. For example, a member could receive case management services because of a behavioral health problem on one referral into case management, and, on the next referral, the same member could receive case management services due to a bone fracture. Thus, each time an individual received case management services, the primary diagnosis might be retained, as might typically be the case for a chronic illness, or could change due to a change in condition for each episode of care.

The primary diagnoses of the 16,713 referrals that received case management services fell into 921 unique classifications utilizing the International Classification of Diseases (ICD-9) (Practice Management Information Corporation, 1996), thus demonstrating that the Case Management Unit handled consumers with a wide variety of presenting diagnoses and resulting psychosocial problems.

The ICD-9 classification system is elaborate and specific. For example, among the 921 diagnoses of consumers who used services of the Case Management Unit, there were nine different codes for bipolar disorders, 22 for substance abuse, 10 for high-risk pregnancies, and 14 for diabetes. For analyses purposes, these 921 unique diagnoses were reclassified into 11 general categories and an "other" category for those diagnoses that did not fit into one of the 11 categories. The 12 reclassified categories included: 1) AIDS/HIV, 2) Bipolar Disorders, 3) Depression, 4) Alcohol/Drug Abuse, 5) Asthma, 6) Diabetes, Injury/Trauma/Fractures, 8) HighRisk Pregnancy, 9) Normal Pregnancy, 10) Congenital Anomalies, 11) Neurological Diagnosis/Cerebrovascular Disease, and 12) Other. When reclassified, the distribution of diagnoses addressed through case management services revealed that High-Risk Pregnancy accounted for $10.7 \%$ of the diagnoses, Injury/Trauma/ Fractures accounted for $6.8 \%$, Normal Pregnancy accounted for 6.7\%, Depression accounted for $5.4 \%$, Neurological Diagnoses/Cerebrovascular Disease accounted for $5.1 \%$, Asthma accounted for 5.0\%, Alcohol/Drug Abuseaccounted for $2.7 \%$, Diabetes accounted for 2.6\%, Congenital Anomalies accounted for $1.8 \%$, AIDS/HIV accounted for $1.6 \%$, Bipolar Disorders accounted for $1.1 \%$, and Other accounted for the remaining $50.6 \%$ of the diagnoses. The "Other" category is quite high because it included several hundred diagnoses. However, each oneaccounted for less than one percent of the total diagnoses.

\section{Social Work Case Management Roles and Functions}

The working environment at the managed care organization reflected an integration of aspects of both social welfare and business paradigms. The public mandate to serve the Medicaid consumer was a priority within the Case Management Unit. On the other hand, the corporate mandate to be efficient and cost-effective was also routinely evident. Usually, the two mandates could be accomplished by staff within the Unit without any professional conflict of interest. When the public man- 
date and the corporate mandate conflicted, however, the Case Management staff conferred with other co-workers in this interdisciplinary unit and with supervisors, including the Unit manager and the health plan medical director. They weighed the benefits and costs to the individual consumers before making any decisions. This allowed for a more informed decision-making process and facilitated a collaborative approach to conflict resolution. An example of such a conflict would be in a case where a prescribed medication that the primary physician had ordered was not included in the organization's drug formulary. For a special needs consumer, the task of case managers would be to advocate for a waiver to permit the consumer to receive the prescribed medication. Case managers reported that their advocacy efforts were usually successful.

When asked to describe their duties, roles, and responsibilities as case managers, all eight individuals identified coordination of services and service as a resource specialist for members. Four of the case managers considered themselves member advocates, with one case manager describing empowerment of members as a key job function. Other job functions described by case managers included: consultation with providers, crisis management, development and monitoring of treatment plans, education of the member, promotion of good health practices, and service as a liaison between the member and community services. One case manager described her function as "assisting members in getting appropriate, costeffective care in a timely fashion." Irrespective of their professional identification as a social worker, nurse, or rehabilitation counselor, all eight case managers responded by identifying job functions performed by professional case managers and not necessarily those of their individual professions.

The Case Management Unit used a social case management model staffed primarily with social workers. However, as the department expanded, it developed an interdisciplinary approach to case management by adding the other professional disciplines of nursing and rehabilitation counseling. All but one of the case managers interviewed felt that this interdisciplinary approach influenced what they did as case managers. The case managers generally felt that the collaboration and consultation among staff from different disciplines allowed them to become better informed and more efficient in decision-making.

There was a high level of comfort among the social workers that functioned within an interdisciplinary approach while utilizing their special ized discipline specific skills to address individual consumer needs. There were few value conflicts or professional conflicts observed or reported among Unit staff. Social work case managers reported performing similar functions to those used by social workers in the community setting (i.e., advocacy, counseling, coordination, brokering, program development). Generally, they did not view their telephone interventions with consumers and providers as problematic. According to all case management staff, providing services through community providers also appeared to work well when the consumer and provider had developed a good working relationship.

There were instances where case managers had to advocate for members' needs that were not covered by the health plan. Some of these advocacy efforts (such as a member needing supplies or medications) may have cost the health plan more in the short-run, but in the long-run was considered preventative and cost-effec- 
tive in nature. Staff indicated that they were comfortable working within this corporate setting, and it appeared that they were well respected by other units throughout the managed care company.

As a profession, social work has been lukewarm regarding its role in providing services within corporate managed care settings primarily because of our unfamiliarity with managed care, lack of direct access to the managed care policymaking process, and the desire to adhere to the profession's ethics and values (Epstein \& Aldredge, 2000). In contrast, case management staff within this Managed Care Organization possessed a clear understanding of the organization's role in providing health care delivery, their role as advocates and facilitators in securing necessary and appropriate services, and their potential to impact organizational policies and procedures that affected the overall health of consumers.

Benefits of interdisciplinary case management included the convergence of perspectives, more in-depth assessment, and a more holistic approach to service. None of the workers could identify any specific weaknesses with the interdisciplinary approach. One suggested that "the informal nature of their professional collaboration might need to be formalized in the future should the department grow significantly." When asked what other disciplines should be added to the Case Management Unit, all but one of the case managers suggested that additional staff should have a background in the area of developmental disabilities. Other suggested areas of expertise for new staff were in benefits and funding, early intervention and education, behavioral health, community outreach, home health, and rehabilitation and orthotics. One worker felt that until the needs of the growing membership could be determined, it was premature to anticipate what additional areas of expertise would be needed within the Case Management Unit.

Staff indicated their concern that communication among unit case managers might be challenged as additional professionals are added to the unit and new procedures for addressing larger numbers of high-risk populations emerge. Staff indicated that the interdisciplinary approach was well-integrated into daily operations of the Case Management Unit. Utilizing a quality improvement mechanism to address staffing loads, communication patterns, case management policies and procedures, documentation of case findings, and consumer outcome measures could enhance successful future growth of the Case Management Unit.

\section{Consumer Satisfaction}

In general, members who participated in the focus groups were very positive about the health plan and the case management services they received. Members who interfaced with case management were much more favorable than those who had not. Indicative of the enthusiasm demonstrated by members who had interfaced with case management staff, some described the health plan as "Miracle Insurance" and a "Thank You Health Plan." Members who interfaced with case managers reported that the case manager listened and responded to their needs, remembered who they were, indicated genuine concern for their unique health concerns, had good communication skills, and were knowledgeable about resources. Members generally noted prompt follow-up by case managers following hospitalizations and member-initiated calls to theUnit. Of significant help was the 
brokering role of case management, where case managers linked members to other health plan services, such as a high-risk maternity program, or to community agencies providing services for alcohol or drug problems, mental health issues, special needs children, and the like. Members noted the tangible services they received, such as assistance with alcohol rehabilitation assistance, transportation, rehabilitation therapies, maternity outreach assistance, medical equipment, information on available services, and coordination of services prior to and after hospitalization. They were particularly pleased that case managers understood their needs, were kind and respectful, and were resourceful. They acknowledged the efficient manner in which the Case Management Unit appeared to operate.

Some members who did not have direct contact with the health plan case managers did receive case management services from providers and vendors who served them following an illness or injury. Members of this group generally felt pleased with the services they received from the providers and vendors who assisted them in the home. These services, many of which were arranged by the case managers, included home health assistance with insulin training, high-risk pregnancy bed rest with home health and homemaker assistance, and orthotics with follow-up physical therapy. Generally, these members were pleased with the prompt arrangements for services, the effectiveness of the service, and the quality of the personnel providing the services. One member indicated that "I wouldn't change if I had the choice."

Although members were quite satisfied with case management services, both groups of members - those who had interfaced with case management and those who had not-provided suggestions for the improvement of services. Some suggestions that related to case management interventions included: assistance with prescriptions not covered under the health plan, education of procedures for emergency room visits and ambulance transport, assistance in obtaining respite help and parenting skills in dealing with challenged children, and assistance in locating providers within the health plan network for their unique family needs. Suggestions related to overall services provided both in the home and for followup of chronic conditions included: the need for information on continuity of care decisions, future involvement of the member in the decision-making process on services, education of procedures for emergency room visits, a desire to have one primary provider and not multiple providers at a PCP site, and referrals to specialists for chronic care problems.

\section{CONCLUSIONSAND IMPLICATIONS}

The utilization of social workers within managed care organizations is a recent development. This case study represents an effort to describe this phenomenon. An exploratory-descriptive design permitted a broad assessment of social workers utilizing case management services at a specific health plan and demonstrated the perceived effectiveness of case management in delivering Medicaid HMO services to vulnerable high-risk populations. The findings of the semi-structured interviews, the focus groups, and the participant observation indicated that the use of case management services, delivered primarily by social workers, were effective in addressing bio-psychosocial needs of Medicaid consumers within a provider-driven managed care system. 
This case study demonstrated that social workers utilizing case management skills are highly effective in a managed care organization, suggesting that other managed care organizations can employ social workers to improve the quality of services. However, individualized attention to client needs is essential to effective case management. In this case study, the interdisciplinary approach to the delivery of case management services maximized the capabilities and unique talents of personnel in the Case Management Unit. Other managed care organizations interested in emulating this model should consider having social workers at the core of such a unit. Successful delivery of case management services included formal linkages with community-based organizations that were maintained through ongoing quality assessment and improvement activities. Consequently, other managed care organizations employing this case management model would be wise to develop strong linkages and relationships with community-based organizations.

Social workers interested in seeking careers in managed care organizations need to garner specific skills for such practice. In studying the growth of managed care and its effect on the training of professional social workers, Strom-Gottfried (1997); Strom-Gottfried, et al. (1998); and Jarman-Rohde, McFall, Kolar, and Strom (1997) recommended additional training of social workers and social work students in managed care. Black (1997) identified several competencies for emerging professionals in managed care that will be needed within the near future. These include familiarity with the systems' perspective, familiarity with multidisciplinary teams both within and across organizations, computer literacy, data analysis skills, familiarity with management techniques, knowledge of case management, familiarity with epidemiological research techniques, and interpersonal skills that assist the consumer and the community (Black, 1997). Professional skills for practice need to be focused in three areas: basic professional skills, population-specific skills, and autonomy-building skills (New York Academy of Medicine, 2000). There may be a growing gap between the training given social work students and the real-life needs of health care consumers (CSWE, 1998; The New York Academy of Medicine, 2000). If so, emerging professionals will benefit from specific training on the actual mechanics of managed care systems and how they operate. Such specialized training might include coverage of health care delivery systems, health care policy issues and analysis, medical terminology, outcomes measurement research and program evaluation techniques, accountability techniques, development of individual treatment plans, and health promotion and disease prevention strategies. As social workers serve as both primary care providers and function in a variety of case management roles within managed care settings, a thorough understanding of the managed care environment is essential (National Association of Social Workers, 2000). In the future, case management will increasingly be applied to chronic disease care management (The Institute for the Future, 2000). Educators need to examine their curricula and field placement options to ascertain how they relate to the competencies and skills demanded from managed care organizations. Social work educators will need to enlighten policymakers on the state and local level of the value and need for professional social workers within managed care systems. Future health care delivery systems will provide new employment opportunities for social workers and other allied health professionals. As managed care systems employ a wide variety of disciplines and profession- 
als to staff this growing field, research conducted with managed care systems will strengthen pre-employment training. On-site participant observation can be highly valuable in developing foundation knowledge about emerging service delivery environments such as managed care.

While much has been learned about the utilization of case management at a Medicaid managed care organization, a major limitation is that only one Case Management Unit at one Medicaid managed care organization was examined. Therefore, the findings of this case study are limited in their generalizability. Nonetheless, the implementation of a social case management model with highrisk populations may prove to be as effective in other locations where similar populations are served by managed care organizations committed to providing quality services.

A possible confounding factor in this study is that of social desirability. Even though the interviews with the case managers appeared to be balanced and objective, there may have been a bias with presenting information in a manner that would positively reflect upon the Case Management Unit and the health plan. Similarly, and perhaps even more of a factor could be the responses by the consumers in the focus groups. Historical recall of the services received was difficult for a few consumers, and some may have been reluctant to mention service delivery problems even though confidentiality was assured. Some consumers might have felt intimidated when participating in the study or even fearful of sharing any negative experiences. These factors could have contributed to the high regard that the consumers held for the Case Management Unit and the health plan. Nonetheless, the perceptions of the consumers allowed for an understanding of their basic heal th care needs. These perceptions provided a basis for understanding the primary impact of social work case management services upon high-risk consumers.

Subsequent replication of this study should be conducted in other Medicaid settings and in the private, commercial, managed care arena with larger populations. Such replication would be prudent in light of continued scrutiny of managed care arrangements by policymakers and consumer groups. Additionally, continued research and examination of best practices will assist stakeholders to modify and improve Medicaid managed care in order to safeguard particular populations. In particular, the delivery of social work case management to vulnerable high-risk populations should receive increased attention due to the aging of the population and the subsequent increase in related bio-psychosocial needs. This case study indicated high consumer satisfaction by high-risk populations with case management services. Further research is needed to ascertain future consumer satisfaction as more heterogeneous high-risk populations enroll in managed care arrangements. Research comparing customer satisfaction and health perceptions for those high-risk populations under traditional fee-for-service and Medicaid $\mathrm{HMO}$ arrangements would enlighten policymakers in addressing the challenging and unique needs of this population. Replication of this case study within other Medicaid HMOs serving similar high-risk populations in other states would be beneficial to policymakers as they implement mandatory managed care for Medicaid recipients as part of welfare reform initiatives. 


\section{References}

Black, J. T. (1997, May 5). The revolution in health care: Trends and implications. Public Health Social Work InstitutePresentation. Pittsburgh, PA.

Council on Social Work Education. (1998). Report identifies health care issues affecting social work education. Social Work Education Reporter, 46(3), 8.

Epstein, M., \& Aldredge, P. (2000). Good but not perfect: A case study of managed care. Needham Heights, MA: Allyn and Bacon.

Goldsmith, J. C., Goran, M. J., \& Nackel, J. G. (1995). Managed care comes of age. Healthcare Forum Journal, 38(5), 14-24.

Harris, N. (1992). What's ahead in health care for 1993? Business and Health, 12, 32-38.

Hughes, W. C. (1999). Managed care, meet community support: Ten reasons to include direct support services in every behavioral health plan. Health and Social Work, 24(2), 103-111.

The Institute for the Future. (2000). Health and health care2010: Theforecast, thechallenge San Francisco, CA: Jossey-Bass.

Jarman-Rohde, L., McFall, J., Kolar, P., \& Strom, G. (1997). The changing context of social work practice: Implications and recommendations for social work educators. Journal of Social Work Education, 33(1), 29-45.

Kaiser Commission on the Future of Medicaid. (1995). Medicaid and managed care: Lessonsfrom theliterature. Menlo Park, CA: The HenryJ. Kaiser Family Foundation.

Kelly, J. (1997). Medicaid reform. University of Pittsburgh Institute of Politics Report, 15, 1-2.

Landgarten, S. (1988). Introduction. In K. Fisher \& E. Weisman (Eds.) Case management: Guiding patients through the health care maze Chicago, IL: The Joint Commission on Accreditation of Healthcare Organizations.

McManus, M., Fox, H., \& Newacheck, P. (1996). Strengthening partnerships between stateprogramsfor children with special health needs and managed care organizations. Rockville, MD.: Maternal and Child Health Bureau.

Meyers, M., Lukemeyer, A., \& Smeeding, T. (1998). The cost of caring: Childhood disability and poor families. Social Service Review, 72(2), 209-233.

Moore-Greene, G. (2000). Standardizing social indicators to enhance medical case management. Social Work in Health Care, 30(3), 39-53.

National Association of Social Workers. (1992). NASW standards for social work case management. Washington, DC: National Association of Social Workers.

National Association of Social Workers. (2000). Social work speaks: National Association of Social Workers policy statements 2000-2003 ( $5^{\text {th }}$ ed.). Washington, DC: NASW Press.

The New York Academy of Medicine. (2000). Social work education for practicein health care: Final report. Second Edition. New York, NY: Author.

Nicolaysen, L. (1996). More than just utilization review. Continuing Care, 3, 22-25.

Pew Health Care Professions Commission. (1995). Critical challenges: Revitalizing the health care professions for thetwenty-first century. San Francisco, CA: UCSF Center for the Health Professions.

Practice Management Information Corporation. (1997). International classification of diseases $9^{\text {th }}$ revision: Clinical modification ( $5^{\text {th }}$ ed.). Los Angeles, CA: Practice Management Information Corporation.

Preister, S. (1996). An opportunity for family-based reform. Empowering Families, 5(2), 3-13.

Shatin, D., Levin, R., Ireys, H., \& Haller, V. (1998). Health care utilization by children with chronic illness: A comparison of Medicaid and employer-insured managed care. Pediatrics, 102(4), 966.

Smith, D. S. (1995). Standards of practice for case management: The importance of practicestandards. The Journal of Care Management, 1(3), 6-16.

Somers, S. A., \& Martin, R. M. (1997). Key issue to address in Medicaid managed care's future: Populations with special needs. Managed Medicareand Medicaid Perspectives, January, 27, 1997, 1-4. 
Strom-Gottfried, K. (1997). The implications of managed care for social work education. Journal of Social Work Education, 33(10), 7-18.

Strom-Gottfried, K., \& Corcoran, K. (1998). Confronting ethical dilemmas in managed care: Guidelines for students and faculty. Journal of Social Work Education, 34(1), 109-119.

U.S. Department of Health and Human Services Health Care Financing Administration Press Office. (1997, January 28,). Managed care in Medicareand Medicaid. Washington, DC: Author.

U.S. Department of Health and Human Services-HCFA. (2000, July 13). National summary of Medicaid managed care programs and enrollment. Washington, DC: Author.

U.S. General Accounting Office. (1996). Medicaid managed care: Serving the disabled challenges state programs. (GAO/HEHS-96-136). Washington, DC: U. S. Government Printing Office.

\section{Author's Note:}

Address correspondence to: Dr. Lisa S. Patchner, Ball State University, Social Work Department, AR 227, Muncie, IN 47306-0525 USA. E-mail: Ipatchner@bsu.edu. 